\title{
A cross-cultural clinical comparison between subjects with obsessive- compulsive disorder from the United States and Brazil
} \author{
Ygor A. Ferrão ${ }^{g}$, Jon E. Grant ${ }^{\mathrm{a}}$ \\ a Department of Psychiatry \& Behavioral Neuroscience, University of Chicago, Chicago, IL, United States of America \\ b Botucatu Medical School-São Paulo State University (UNESP), Botucatu, SP, Brazil \\ c Alpert Medical School of Brown University, Providence, RI, United States of America \\ d Department of Psychiatry, Mount Sinai St. Lukes/Mount Sinai West, New York, NY, United States of America \\ e Institute of Psychiatry, Universidade Federal do Rio de Janeiro (UFRJ), Rio de Janeiro (RJ), Brazil \\ ${ }^{\mathrm{f}}$ Department of Psychiatry and Psychology, Federal University of São Paulo, São Paulo (SP), Brazil \\ ${ }^{\mathrm{g}}$ Porto Alegre Health Sciences Federal University, Rio Grande do Sul, Porte Alegre/RS, Brazil
}

Gustavo C. Medeiros ${ }^{\mathrm{a}, *}$, Albina R. Torres ${ }^{\mathrm{b}}$, Christina L. Boisseau ${ }^{\mathrm{c}}$, Eric W. Leppink ${ }^{\mathrm{a}}$, Jane L. Eisen ${ }^{\mathrm{d}}$, Leonardo F. Fontenelle ${ }^{\mathrm{e}}$, Maria C. do Rosário ${ }^{\mathrm{f}}$, Maria C. Mancebo ${ }^{\mathrm{c}}$, Steven A. Rasmussen ${ }^{\mathrm{c}}$,

\section{A R T I C L E I N F O}

\section{Keywords:}

Obsessive-compulsive disorder

Clinical aspects

Transcultural psychiatry

Cross-cultural psychiatry

\begin{abstract}
A B S T R A C T
Although OCD is a global problem, the literature comparing, in a direct and standardized way, the manifestations across countries is scarce. Therefore, questions remain as to whether some important clinical findings are replicable worldwide, especially in the developing world. The objective of this study was to perform a clinical comparison of OCD patients recruited in the United States (U.S.) and Brazil. Our sample consisted of 1187 adult, treatment-seeking OCD outpatients from the U.S. $(n=236)$ and Brazil $(n=951)$. With regards to the demographics, U.S. participants with OCD were older, more likely to identify as Caucasian, had achieved a higher educational level, and were less likely to be partnered when compared to Brazilians. Concerning the clinical variables, after controlling for demographics the two samples presented largely similar profiles. Brazilian participants with OCD, however, endorsed significantly greater rates of generalized anxiety disorder and posttraumatic stress disorder, whereas U.S. subjects were significantly more likely to endorse a lifetime history of addiction (alcohol-use and substance-use disorders). This is the largest direct cross-cultural comparison to date in the OCD field. Our results provide much needed insight regarding the development of culture-sensitive treatments.
\end{abstract}

\section{Introduction}

Obsessive-compulsive disorder (OCD) is a chronic illness and one of the most impairing mental disorders worldwide (Ruscio et al., 2010; Grant, 2014). Studies conducted in different countries suggest that OCD is associated not only with poor social functioning and low quality of life, but also with a considerable burden on their families and caregivers (Koran, 2000; Ramos-Cerqueira et al., 2008). OCD is a global problem; however, the literature comparing the manifestations across countries in a standardized way is scarce (Koran, 2000; Fontenelle et al., 2004; Ramos-Cerqueira et al., 2008). This is worrisome, since the scientific research on mental health across countries is unequal and concentrated (Fontenelle et al., 2004; Maj, 2005; Saxena et al., 2006; Patel and Kim, 2007; Yorulmaz et al., 2010; Nedeljkovic et al., 2012). For example, the 14 leading highincome nations contributed $90 \%$ to internationally accessible mental health literature (Saxena et al., 2006). Nonetheless, the majority of the world's population lives in developing countries (Maj, 2005; Patel and Kim, 2007; United Nations, 2013). Therefore, questions remain as to whether important clinical findings are replicable worldwide, especially in the developing world. In this context, cross-cultural studies are needed and may help us better understand the replicability of the OCD clinical presentation.

Culture is described as the collective, learned, mind structure that differentiates the individuals from one group to another (Hofstede, 1991; Arrindell et al., 1997). Hofstede claims that culture represents for humans what software means for computers: a psychic programming that frames the way we think, feel and behave (Hofstede, 1991). It is possible to study cultural elements using different approaches such as dividing subjects based on demographic or personality features. On a broader level, we may investigate the culture of a country using the

\footnotetext{
* Correspondence to: Department of Psychiatry \& Behavioral Neuroscience, University of Chicago, 5841 S. Maryland Ave., Office B-344, Chicago, IL 60637, USA.

E-mail address: gcmedeiros@live.com (G.C. Medeiros).
} 
group of environmental and social variables that interact and affect the health of larger populations (Arrindell et al., 1997). In this context, the investigation of how culture may affect the clinical presentation of OCD in different countries might provide valuable insights regarding the elements that shape the disorder.

Previous indirect cross-national comparisons (i.e. analyses of independent studies) in OCD have suggested that some significant differences across countries might be due to sociocultural factors. First, the content of obsessions and compulsions seems to be different depending on the sociocultural background (Fontenelle et al., 2004; de Silva, 2006; Yorulmaz et al., 2009, 2010; Yorulmaz and Işık, 2011). Second, the rates of co-occurring psychiatric disorders may vary according to the country where the research was conducted (Fontenelle et al., 2004; de Silva, 2006; Yorulmaz et al., 2009, 2010; Yorulmaz and Iş1k, 2011). Additionally, age of onset may be affected by sociocultural background and life events (Millet et al., 2004; Cromer et al., 2007). Variables such as co-occurring psychiatric disorders and age of OCD onset affect response to pharmacotherapy and psychotherapy. Therefore, possible cross-cultural differences in OCD presentation have clinical and research relevance (Ackerman et al., 1994; Lensi et al., 1996). However, little is known regarding how culture may influence the clinical presentation of OCD.

The United States (U.S.) and Brazil are two countries with important cultural differences. According to Hofstede (2017), who investigated in detail cultural dimensions in several countries, some of the most relevant discrepancies are: a) Brazilians tend to respect more power positions and hierarchy (i.e. higher scores in the dimension power distance when compared to the U.S.); b) Brazilians tend to be more collectivist than Americans. In other words, there is a higher level of interdependence among the society members in this Latin American country; c) overall, Brazilians are less driven by personal achievement and success and tend to prioritize quality of life and leisure time; d) Brazilians are less attached to norms and time-honored traditions than people from the U.S; and e) Brazilians tend to present lower levels of indulgence, the tendency to seek pleasure and gratification of natural impulses associated with joy and fun (Hofstede, 2017). Given these differences in the cultural background, a cross-cultural comparison between the two countries seems warranted. Additionally, the U.S. and Brazil are two populous nations with large academic centers and established research on OCD. These factors facilitate the recruitment and study of large clinical samples.

With respect to comparisons between the U.S. and Brazil on OCD presentation, the evidence has historically relied on indirect comparisons between independent studies (Fontenelle et al., 2004). The lack of direct and standardized research reflects the methodological difficulties in performing cross-national comparisons (Canino et al., 1997). Previous clinical comparisons between the two countries suggest that individuals with OCD from Brazil may have an earlier age of onset of the disorder (Fontenelle et al., 2004). However, the definition of age at onset varies among different independent studies (Fontenelle et al., 2004). Research has associated early onset of OCD with environmental stress (Marks, 1987; Fostick et al., 2012). A higher criminality (Murray et al., 2013) and a lower quality life in Brazil might lead to an earlier onset of OCD. These problems may also help to explain the higher rates of generalized anxiety disorder (GAD) in OCD patients of this Latin American country (Fontenelle et al., 2004; Ruscio et al., 2010). Studies also suggested lower rates of cooccurring alcohol and substance use disorders in OCD patients from Brazil when compared to subjects from the U.S (Pinto et al., 2006; Miguel et al., 2008). However, the independent studies have substantially different methodologies. For example, they have different: a) sources of recruitment (outpatient versus inpatient versus mixed sources); b) inclusion and exclusion criteria; c) diagnostic instruments; and d) definitions of age at OCD onset (Fontenelle et al., 2004). The question remains as to whether direct and standardized comparisons may better test these hypotheses and improve our understanding of possible cross-national differences in OCD presentation.
The objective of this study was to perform a direct and standardized clinical comparison of treatment-seeking OCD patients recruited in the U.S. and Brazil. The two samples used similar recruitment criteria and assessment instruments. A direct comparison between subjects from the two countries (i.e. "with data on hands") will present several advantages such as: a) establishment of clear inclusion and exclusion criteria; b) standardization of variables such as demographics, definition of age at onset, and progression from first symptoms to full-blown OCD; and c) possibility of performing additional statistical analysis as, for example, correction for confounders. These advantages may provide more precise information than previous independent studies. Our main hypotheses were: 1) Brazilian subjects with OCD will report an earlier onset of the disorder when compared to the U.S. sample (Fontenelle et al., 2004; Murray et al., 2013); 2) Brazilians with OCD will demonstrate a higher prevalence of GAD when compared to the U.S. subjects (Pinto et al., 2006; Miguel et al., 2008; Murray et al., 2013), and 3) the Brazilian sample with OCD will have lower rates of alcohol and substance-use disorders than the U.S. group (Pinto et al., 2006; Miguel et al., 2008).

Aims of the study: The objective of this study was to perform the largest direct clinical comparison in OCD. We analyzed samples collected in the United States and Brazil using similar recruitment criteria and assessment instruments.

\section{Methods}

\subsection{Sample and recruitment}

Our sample consisted of 1187 adult, treatment-seeking OCD outpatients from the U.S. $(n=236)$ and Brazil $(n=951)$. The U.S. sample included individuals recruited through the National Institute of Mental Health-funded Brown Longitudinal Obsessive-Compulsive Study (BLOCS). This is an observational study of adults with OCD enlisted from several psychiatric treatment settings in Rhode Island and Massachusetts (Pinto et al., 2006). Since the assessments in the BLOCS were conducted by different professionals, an evaluation of inter-rater reliability was conducted. The reliability assessment was made comparing the ratings of the professionals to audiotaped interviews. The interviewers independently answered the Structured Clinical Interview for the Diagnostic and Statistical Manual of Mental Disorders Version IV -Axis I (SCID-I for DSM-IV) (First et al., 1997) and the Yale-Brown Obsessive Compulsive Scale (Y-BOCS) (Goodman et al., 1989). All professionals who participated in the study presented an inter-rater reliability of .85 or more (i.e. $85 \%$ of the items of the two scales were the same in the independent evaluations) (Pinto et al., 2006). The Brazilian sample was enlisted through the Brazilian Research Consortium on Obsessive-Compulsive Spectrum Disorders (СТOC), a large multi-center initiative that includes outpatients from eight public universities in five Brazilian states (Miguel et al., 2008). In order to assure the reliability of the assessments made by the different services of the CTOC, professionals from each of the universities involved were independently evaluated. They watched videotaped interviews of six or more research subjects and evaluated them using the SCID-I for DSMIV, the Dimensional Yale-Brown Obsessive-Compulsive Scale (DYBOCS) (Rosario-Campos et al., 2006) and the Universidade de Sao Paulo Sensory Phenomena Scale (Miguel et al., 2000). The different interviewers showed high agreement rate presenting an inter-rater reliability of $96 \%$ (i.e. $96 \%$ of the items of the three scales were the same in the independent evaluations of the professionals) (Miguel et al., 2008).

In both samples, data was obtained at intake interviews. All BLOCS assessments were performed by trained research assistants. The CTOC sample was assessed by clinical psychologists and/or psychiatrists with expertise in OCD. Inclusion criteria for this study were: 1) formal OCD diagnosis according to the SCID-I for DSM-IV; 2) outpatient status; 3) 
minimum age of 18 years. Subjects who presented with acute psychosis, a diagnosis of schizophrenia or schizoaffective disorder, organic mental disorders or any other clinical condition that could interfere with the accuracy and quality of the data collected were excluded. In the Brazilian sample, 960 subjects met the inclusion criteria for this study. Nine (.9\%) individuals were excluded: 7 (.7\%) met criteria for schizophrenia and $2(.2 \%)$ presented with schizoaffective disorder. In the U.S. sample, 240 individuals met the inclusion criteria. Four subjects $(1.7 \%)$ were excluded: $1(.4 \%)$ presented with schizophrenia, $1(.4 \%)$ met criteria for schizoaffective disorder and $2(.8 \%)$ presented with organic mental disorders.

\subsection{Measures}

\subsubsection{Demographics}

The participants were assessed for age, gender, ethnicity, marital status, educational status, occupational status, and whether or not they had children. The U.S. group was assessed by the Butler Hospital OCD Database, a standardized instrument that had been used in several previous studies (Pinto et al., 2006). The Brazilian Sample was evaluated with standardized questions from the Associação Brasileira de Instituto de Pesquisa de Mercado - ABIPEME - scale (Miguel et al., 2008). Since the demographic questionnaires were similar but not identical for the two samples, we transformed the data to facilitate comparison between the two groups (i.e. merged some categories to reach more homogenous groups). We used the same demographic categories of research that had been previously published (Lochner et al., 2005; Miguel et al., 2008; Medeiros et al., 2015a, 2015b).

\subsubsection{Use of psychotropic medication}

We assessed, with open questions, the use of any psychotropic medication, selective serotonin reuptake inhibitors (SSRIs) and atypical antipsychotics.

\subsubsection{Clinical variables}

OCD diagnosis, co-occurring psychiatric disorders and age at onset of OCD: This study used the SCID-I for DSM-IV to determine the diagnosis of lifetime OCD. In addition, age at onset of first OCD symptoms and age at onset of full OCD criteria were documented. Based on the above information, we also calculated the time between first obsessive-compulsive symptoms and meeting full diagnostic criteria for OCD.

OCD severity: The Yale-Brown Obsessive Compulsive Scale [Y-BOCS] was used to assess OCD severity. The Y-BOCS is composed of a ten-item overall severity score as well as two sub-scores - obsession score and compulsion score (Goodman et al., 1989). The scale includes questions (time spent, interference, distress, resistance and control) for both obsessions and compulsions. Each item rated from 0 (no symptoms) to 4 (extremely severe symptoms), and the maximum score is 40 ( 20 for obsessions and 20 for compulsions).

\subsection{Statistical analysis}

A univariate comparison between the U.S. and the Brazilian samples was conducted, concerning demographic and clinical variables. We analyzed the distribution of continuous variables using a One-Sample Kolmogorov-Smirnov Test. We performed Pearson's chi-square test and Mann-Whitney's U, respectively, for categorical and continuous variables (all continuous variables evaluated in this study presented nonparametric distribution). Categorical variables with cell sizes equal or lower than 5 subjects were analyzed using Fisher's Exact Test. We also estimated effect sizes using Cramer's $V$ for categorical variables and Cohen's $d$ for continuous variables.

All clinical results controlled for the demographic differences between the groups (i.e. age, ethnicity, educational level, marital status - see results). This correction was conducted using linear regressions - which is a common approach to control for multiple confounders (Pourhoseingholi et al., 2012). As highlighted by Pourhoseingholi and colleagues (2012) "the linear regression analysis is another statistical model that can be used to examine the association between multiple covariates and a numeric outcome. This model can be employed as a multiple linear regression to see through confounding and isolate the relationship of interest" (Pourhoseingholi et al., 2012). This approach has been used in different studies in mental health (Ibáñez et al., 2001; Wilens et al., 2002).

Additionally, we performed a Bonferroni correction to account for multiple comparisonsand set the significance level at .007 (.05/ $7=.007)$ for demographics, at .017 for medication status (.05/ $3=.017)$, and at $.002(.05 / 25=.002)$ for clinical variables.

Finally, we conducted a binary logistic regression (enter method) in which we introduced all the statistically significant clinical variables (input $\mathrm{p} \leq .002$ ) from the previous bivariate comparison. For the clinical variables, we used non-controlled $\mathrm{p}$ values (i.e. not controlled for demographics). This model was used to produce a final model that could suggest the elements that critically discriminate the U.S. from the Brazilian sample. Binary logistic regression is a commonly used method to predict variables when the dependent variable is categorical (especially when we have two groups), and the independent variables are metric or non-metric. This strategy has the advantage of being less influenced by possible violations of basic assumptions (normal distribution and homocesdasticity, for example). Binary logistic regression is not affected by unequal sample sizes in the compared groups (Field, 2005; Hair et al., 2006). A significance level of .05 was used for output in this logistic regression.

\subsection{Ethics}

This study was approved by the Institutional Review Board of all 9 centers that participated in this multicenter research. All subjects provided statements of informed consent prior to enrollment. The study protocol followed the guiding policies and principles for experimental procedures with human beings of the Declaration of Helsinki.

\section{Results}

Concerning the distribution of the continuous variables, all variables presented a non-parametric dispersal. Distribution data for the different variables were: age (skewness $=.539$; kurtossis $=-.439$; range $=64$ ); age at onset of first obsessive-compulsive symptoms (skewness $=2.061$; kurtossis $=6.256$; range $=57$ ); age of OCD onset (skewness $=1.251$; kurtossis $=1.597$; range $=60$ ); progression from first obsessive-compulsive symptoms to OCD (skewness $=1.531$; kurtossis $=2.608$; range $=58$ ); Y-BOCS obsessions severity (skewness $=-.436$. ; kurtossis $=.186$; range $=20$ ); Y-BOCS compulsions severity (skewness $=-.538$; kurtossis $=.125$; range $=20$ ); Y-BOCS overall severity (skewness $=-.317$; kurtossis $=-.207$; range $=33$ ).

With regards to the demographics, U.S. subjects with OCD were older, more likely to identify as Caucasian, had achieved a higher educational level and were less likely to be partnered when compared to Brazilians (see Table 1). Demographic variables that showed differences between the samples (age, ethnicity, educational level, marital status) were carried over to the next steps of statistical analyses, in order to control for differences in the clinical profile.

With respect to medication status, seventy-eight percent $(n=184)$ of the U.S. sample and $56.2 \% \quad(n=534)$ of the Brazilian sample $\left(\chi^{2}=37.648 ; p<.001\right)$ reported using psychotropic medication at the time of the evaluation. SSRIs were used by $61.4 \%(n=145)$ of the U.S. group and $39.2 \%(n=373)$ of the Brazilian group $\left(\chi^{2}=37.951\right.$; $p<.001)$, while atypical antipsychotics were taken by $13.6 \%(n=35)$ of the U.S. participants and $7.8 \%(n=74)$ of the Brazilian subjects $\left(\chi^{2}=11.266 ; p=.001\right)$. Previous research investigating medication status had been published using samples that significantly overlap with 
Table 1

Comparative demographic features of treatment-seeking adults with obsessive-compulsive disorder from the United States $(n=236)$ and Brazil $(n=951)$.

\begin{tabular}{|c|c|c|c|c|c|}
\hline Demographics & $\begin{array}{l}\text { United States } \\
n=236 \\
\text { Mean }\left(\mathrm{SD}^{\mathrm{a}}\right) / \text { Median or } \%(n)\end{array}$ & $\begin{array}{l}\text { Brazil } \\
n=951 \\
\text { Mean (SD) / Median or } \%(n)\end{array}$ & $\begin{array}{l}\text { Statistical Test's } \\
\text { Coefficient }^{\mathrm{b}}\end{array}$ & $\begin{array}{l}\text { Test's } \\
p \\
\text { Value }^{\mathrm{b}}\end{array}$ & $\begin{array}{l}\text { Effect Size } \\
\text { Cohen's } d \\
\text { or Cramer's } V\end{array}$ \\
\hline Age & $39.5( \pm 12.7) / 39.0$ & $35.9( \pm 12.5) / 33.0$ & $\mathrm{U}=92,446$ & $<.001$ & $d=.286$ \\
\hline $\begin{array}{l}\text { Gender } \\
\text { - Male } \\
\text { - Female }\end{array}$ & $\begin{array}{l}42.4(100) \\
57.6(136)\end{array}$ & $\begin{array}{l}41.7(397) \\
58.3(554)\end{array}$ & $\chi^{2}=.031$ & .861 & $V=.005$ \\
\hline $\begin{array}{l}\text { Ethnicity } \\
\text { - Caucasian } \\
\text { - Non-Caucasian }\end{array}$ & $\begin{array}{l}98.3(231) \\
1.7(4)\end{array}$ & $\begin{array}{l}83.0(788) \\
17.0(161)\end{array}$ & $\chi^{2}=36.586$ & $<.001^{\mathrm{c}}$ & $V=.176$ \\
\hline $\begin{array}{l}\text { Educational Level } \\
\text { - High school or less } \\
\text { - More than high school }\end{array}$ & $\begin{array}{l}26.3(62) \\
73.7(174)\end{array}$ & $\begin{array}{l}46.9(446) \\
53.1(504)\end{array}$ & $\chi^{2}=33.004$ & $<.001$ & $V=.167$ \\
\hline $\begin{array}{l}\text { Marital Status } \\
\text { - With partner } \\
\text { - Without partner }\end{array}$ & $\begin{array}{l}43.2(102) \\
56.8(134)\end{array}$ & $\begin{array}{l}60.5(575) \\
39.5(376)\end{array}$ & $\chi^{2}=22.939$ & $<.001$ & $V=.139$ \\
\hline $\begin{array}{l}\text { Occupational Status } \\
\text { - Employed } \\
\text { - Unemployed }\end{array}$ & $\begin{array}{l}52.1(123) \\
47.9(113)\end{array}$ & $\begin{array}{l}52.2(495) \\
47.8(453)\end{array}$ & $\chi^{2}=.001$ & .979 & $V=.001$ \\
\hline $\begin{array}{l}\text { Offspring } \\
\text { - At least } 1 \text { son or daughter } \\
\text { - No son or daughter }\end{array}$ & $\begin{array}{l}50.4 \text { (119) } \\
49.6(117)\end{array}$ & $\begin{array}{l}41.3(393) \\
58.7(558)\end{array}$ & $\chi^{2}=6.382$ & .012 & $V=.073$ \\
\hline
\end{tabular}

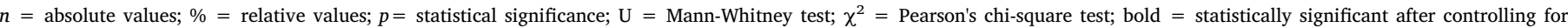
demographics and multiple comparisons.

${ }^{\text {a }} \mathrm{SD}=$ standard deviation.

${ }^{\mathrm{b}}$ Comparison between the United States and Brazil. Significance level for demographics was controlled for multiple comparisons and set at .007 (.05/7 $=.007$ ).

${ }^{\mathrm{c}}$ Fisher's exact test was used due to the small cell size.

ours [see Mancebo and colleagues (2006) for the U.S. group (Mancebo et al., 2006), Brakoulias and collaborators (2016) for the Brazilian sample (Brakoulias et al., 2016).

In terms of OCD symptoms, Brazilian patients exhibited more severe OCD symptoms reflected by the Y-BOCS obsession score and total score in the univariate analysis. However, after introducing statistical controls the difference in overall severity was no longer significant and only the obsessions severity remained statistically higher for Brazilian subjects. The samples did not differ significantly in regards to age at onset of initial OCD symptoms or OCD (see Table 2).

Concerning the lifetime prevalence of co-occurring psychiatric disorders, the two samples presented largely similar profiles. Brazilian participants, however, endorsed significantly greater rates of GAD and post-traumatic stress disorder (PTSD) whereas the U.S. participants with OCD were significantly more likely to endorse a lifetime history of addiction [alcohol-use disorder and substance-use disorder] - see Table 3.

The binary logistic regression model (enter method) comparing the two samples included all clinical variables that differed between the samples $(p<.002)$. The variables entered were Y-BOCS - obsessions severity, GAD, PTSD, alcohol and substance-use disorder. All variables were critically important to discriminate the samples. Forward and the backward strategies also led to the same final model (see table 4).

Table 2

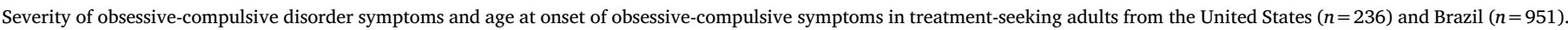

\begin{tabular}{|c|c|c|c|c|c|c|}
\hline Clinical variable & $\begin{array}{l}\text { United States } \\
n=236 \\
\text { Mean }\left(\mathrm{SD}^{\mathrm{a}}\right) / \text { Median }\end{array}$ & $\begin{array}{l}\text { Brazil } \\
n=951 \\
\text { Mean (SD)/Median }\end{array}$ & $\begin{array}{l}\text { Statistical } \\
\text { Test's } \\
\text { Coefficient }^{\mathrm{b}}\end{array}$ & $\begin{array}{l}\text { Test's } \\
p \\
\text { Value }^{\mathrm{b}}\end{array}$ & $\begin{array}{l}\text { Effect } \\
\text { Size } \\
\text { Cohen's } d\end{array}$ & $\begin{array}{l}\text { Controlled } \\
p \\
\text { Value }^{\mathrm{c}}\end{array}$ \\
\hline \multicolumn{7}{|l|}{ Severity of OCD Symptoms (YBOCS ${ }^{\mathrm{d}}$ ) } \\
\hline - Obsessions severity & $11.5( \pm 3.2) / 12.0$ & $12.7( \pm 3.9) / 13.0$ & $\mathrm{U}=87,596.0$ & $<.001$ & $d=.336$ & $<.001$ \\
\hline - Compulsions severity & $12.1( \pm 3.3) / 13.0$ & $12.9( \pm 4.1) / 13.0$ & $\mathrm{U}=96,339.0$ & .001 & $d=.215$ & .058 \\
\hline - OCD overall severity & $23.6( \pm 5.8) / 24.0$ & $25.6( \pm 7.4) / 26.0$ & $\mathrm{U}=91,421.5$ & $<.001$ & $d=.301$ & .004 \\
\hline \multicolumn{7}{|l|}{ Age at Onset of Obsessive-Compulsive Symptoms } \\
\hline - Age at onset of first obsessive-compulsive symptoms (years) $\left[\mathrm{N}^{\mathrm{e}}=1129\right]$ & $11.6( \pm 7.8) / 10.0$ & $12.7( \pm 7.4) / 10.0$ & $\mathrm{U}=85,423.0$ & .003 & $d=.145$ & .040 \\
\hline - Age at onset of OCD (years) $[\mathrm{N}=1168]$ & $22.0( \pm 10.6) / 20.0$ & $22.3( \pm 10.6) / 20.0$ & $\mathrm{U}=107,693.0$ & .675 & $d=.028$ & .003 \\
\hline $\begin{array}{l}\text { - Progression from first obsessive-compulsive symptoms to OCD } \text { (years) }^{\mathrm{f}} \\
\quad[\mathrm{N}=1121]\end{array}$ & $10.2( \pm 8.6) / 8.0$ & $9.5( \pm 9.8) / 7.0$ & $\mathrm{U}=87685.0$ & .028 & $d=.076$ & .239 \\
\hline
\end{tabular}

$n=$ absolute values; $p=$ statistical significance; $\mathrm{U}=$ Mann-Whitney test; $\chi^{2}=$ Pearson's chi-square test; bold $=$ statistically significant after.

controlling for demographics and multiple comparisons.

${ }^{\text {a }} \mathrm{SD}=$ standard deviation.

${ }^{\mathrm{b}}$ Comparison between the United States and Brazil. Significance level for clinical variables was controlled for multiple comparisons and set at $.002(.05 / 25=.002)$.

c Controlled for age, ethnicity, educational level and marital status.

${ }^{\mathrm{d}}$ Yale-Brown Obsessive Compulsive Scale (YBOCS).

${ }^{\text {e }} \mathrm{N}=$ number of valid subjects for the variable. When $\mathrm{N}$ is not displayed, all the subjects $(n=1187)$ were evaluated.

${ }^{\mathrm{f}}$ Time between onset of first obsessive-compulsive symptoms and full-blown OCD. 
Table 3

Lifetime prevalence of co-occurring psychiatric disorders in adults with obsessive-compulsive disorder (OCD) from the United States of America ( $n=236)$ and Brazil $(n=951)$.

\begin{tabular}{|c|c|c|c|c|c|c|}
\hline Co-occurring psychiatric disorder & $\begin{array}{l}\text { United States } \\
n=236 \\
\%(n)\end{array}$ & $\begin{array}{l}\text { Brazil } \\
n=951 \\
\%(n)\end{array}$ & $\begin{array}{l}\text { Statistical } \\
\text { Test's } \\
\text { Coefficient }^{\mathrm{a}}\end{array}$ & $\begin{array}{l}\text { Test's } \\
p \\
\text { Value }^{\mathrm{a}}\end{array}$ & $\begin{array}{l}\text { Effect } \\
\text { Size } \\
\text { Cramer's } V\end{array}$ & $\begin{array}{l}\text { Controlled } \\
p \\
\text { Value }^{\mathrm{b}}\end{array}$ \\
\hline \multicolumn{7}{|l|}{ OCD spectrum/tic disorders } \\
\hline - Body dysmorphic disorder & $8.9(21)$ & $11.6(110)$ & $\chi^{2}=1.338$ & .247 & $V=.034$ & .613 \\
\hline - Trichotillomania & $2.6(6)$ & $6.3(60)$ & $\chi^{2}=5.085$ & .024 & $V=.066$ & .065 \\
\hline - Skin picking disorder $\left[\mathrm{N}^{\mathrm{c}}=1150\right]$ & $14.1(29)$ & $16.6(157)$ & $\chi^{2}=.756$ & .384 & $V=.026$ & .610 \\
\hline - Tourette's syndrome & $4.3(10)$ & $8.1(77)$ & $\chi^{2}=4.105$ & .043 & $V=.059$ & .022 \\
\hline \multicolumn{7}{|c|}{ Anxiety and trauma/stress-related disorders } \\
\hline - Panic Disorder & $22.1(52)$ & $15.8(150)$ & $\chi^{2}=5.385$ & .020 & $V=.067$ & .045 \\
\hline - Generalized anxiety disorder & $9.8(23)$ & $34.1(324)$ & $\chi^{2}=53.801$ & $<.001$ & $V=.213$ & $<.001$ \\
\hline - Post-traumatic stress disorder & $8.9(21)$ & $19.5(185)$ & $\chi^{2}=14.566$ & $<.001$ & $V=.111$ & $<.001$ \\
\hline - Social phobia & $31.5(74)$ & $35.2(334)$ & $\chi^{2}=1.123$ & .289 & $V=.031$ & .831 \\
\hline \multicolumn{7}{|l|}{ Mood disorders } \\
\hline - Major depressive disorder & $65.5(154)$ & $64.9(617)$ & $\chi^{2}=.035$ & .851 & $V=.005$ & .931 \\
\hline - Dysthymia & $8.1(19)$ & $12.1(115)$ & $\chi^{2}=2.955$ & .086 & $V=.050$ & .741 \\
\hline - Bipolar disorder & $3.0(7)$ & $5.6(53)$ & $\chi^{2}=2.687$ & .101 & $V=.048$ & .084 \\
\hline \multicolumn{7}{|l|}{ Addictions } \\
\hline - Alcohol-use disorder & $19.6(46)$ & $8.0(76)$ & $\chi^{2}=27.395$ & $<.001$ & $V=.152$ & $<.001$ \\
\hline - Substance-use disorder & $10.7(25)$ & $4.4(42)$ & $\chi^{2}=13.938$ & $<.001$ & $V=.109$ & $<.001$ \\
\hline - Pathological gambling [N $=1150]$ & $2.4(5)$ & $.6(6)$ & $\chi^{2}=5.787$ & $.031^{\mathrm{d}}$ & $V=.071$ & .007 \\
\hline \multicolumn{7}{|l|}{ Eating disorders } \\
\hline - Anorexia nervosa & $2.6(6)$ & $2.6(25)$ & $\chi^{2}=.005$ & .946 & $V=.002$ & .989 \\
\hline - Bulimia nervosa & $3.4(8)$ & $2.8(27)$ & $\chi^{2}=.208$ & .649 & $V=.013$ & .585 \\
\hline \multicolumn{7}{|l|}{ Somatoform disorders } \\
\hline - Hypochondriasis & $1.7(4)$ & $3.5(33)$ & $\chi^{2}=1.955$ & $.209^{\mathrm{d}}$ & $V=.041$ & .346 \\
\hline - Somatization disorder & $.0(0)$ & $2.3(22)$ & $\chi^{2}=5.545$ & $.013^{\mathrm{d}}$ & $V=.068$ & .050 \\
\hline - Pain disorder & $.0(0)$ & $2.9(28)$ & $\chi^{2}=7.094$ & $.003^{\mathrm{d}}$ & $V=.077$ & .020 \\
\hline
\end{tabular}

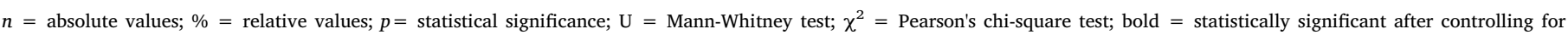
demographics and multiple comparisons.

${ }^{a}$ Comparison between the United States and Brazil. Significance level for clinical variables was controlled for multiple comparisons and set at $.002(.05 / 25=.002)$.

${ }^{\mathrm{b}}$ Controlled for age, ethnicity, educational level and marital status.

${ }^{\mathrm{c}} \mathrm{N}=$ number of valid subjects for the variable. When $\mathrm{N}$ is not displayed, all the subjects $(n=1187)$ were evaluated.

${ }^{\mathrm{d}}$ Fisher's test was used due to the small cell size.

Table 4

Binary logistic regression for American $(n=236)$ and Brazilian $(n=951)$ treatmentseeking adults with obsessive-compulsive disorder $(\mathrm{OCD})^{\mathrm{a}}$.

\begin{tabular}{|c|c|c|c|c|c|}
\hline \multirow[t]{2}{*}{$\begin{array}{l}\text { Final model } \\
\text { Variables }\end{array}$} & \multirow[t]{2}{*}{ Wald $\chi^{2}$} & \multirow[t]{2}{*}{$p$ value } & \multirow[t]{2}{*}{$\begin{array}{l}\text { Odds } \\
\text { Ratio }\end{array}$} & \multicolumn{2}{|c|}{$\begin{array}{l}95 \% \text { Odds Ratio } \\
\text { interval }\end{array}$} \\
\hline & & & & Lower & Upper \\
\hline $\begin{array}{l}\text { - YBOCS obsessions } \\
\text { severity }\end{array}$ & 16.942 & $<.001$ & 1.088 & 1.045 & 1.132 \\
\hline $\begin{array}{l}\text { - Post-traumatic stress } \\
\text { disorder }\end{array}$ & 13.283 & $<.001$ & 2.608 & 1.558 & 4.367 \\
\hline $\begin{array}{l}\text { - Generalized anxiety } \\
\text { disorder }{ }^{\mathrm{b}}\end{array}$ & 45.132 & $<.001$ & 4.972 & 3.114 & 7.939 \\
\hline - Alcohol-use disorder ${ }^{\mathrm{b}}$ & 21.898 & $<.001$ & .328 & .205 & .523 \\
\hline - Drug-use disorder ${ }^{\mathrm{b}}$ & 7.751 & .005 & .415 & .224 & .771 \\
\hline Constant & .371 & .542 & 1.164 & - & - \\
\hline
\end{tabular}

Binary logistic regression internal values: $0=$ American sample, $1=$ Brazilian sample (reference group)

${ }^{\text {a }}$ We used the [enter method] strategy in the binary logistic regression.

b Lifetime prevalence.

c The binary logistic regression final model did not exclude any of the variables that were initially introduced.

\section{Discussion}

We performed a comparison of treatment-seeking OCD patients from the U.S. and Brazil, assessed with direct and standardized instruments. Both samples presented analogous recruitment strategies (treatment-seeking outpatients from university services) that might have resulted in very similar profiles regarding severity of OCD symptoms. In fact, the majority of clinical variables (severity of OCD symptoms, age at onset of obsessive-compulsive symptoms and disorder, and co-occurring psychiatric disorders) was similar between the two samples. There were, however, some relevant differences, particularly in terms of co-occurring psychiatric disorder, that might be important for a deeper understanding of OCD from a cross-cultural perspective.

One of the strengths of our study was the sample size (total $n=1187$ ). We were able to enlist hundreds of participants though a multisite enrollment in the U.S. and in Brazil. A large sample increases the statistical power of the study and may maximize the ability to detect differences between the investigated groups. However, statistical analyses of larger samples might interpret even small or clinically irrelevant differences as statistically significant (Lin et al., 2013). Therefore, solely relying on statistical significance may be misleading. The fact that our research controlled for multiple comparisons (i.e. decreased the level of significance $-p$ value) might partially mitigate this problem. Nonetheless, examining additional statistical indicators such as effect size is very important when dealing with large samples.

Regarding demographic characteristics, findings from this research suggest that core aspects of OCD may be independent of cultural background. For example, despite some demographic differences between the samples, U.S. subjects and Brazilians presented with approximately the same male to female ratio, 1:1.4 and 1:1.3 respectively. A higher percentage of females has been described in different studies around the world and appears to occur in clinical studies and in epidemiological research (Horwath and Weissman, 2000; Fontenelle et al., 2004; Ruscio et al., 2010). Regarding the U.S. and Brazil, a higher proportion of females has also been described in large epidemiologic 
research conducted in the two countries. Ruscio et al. (2010) found that females had OCD more frequently than males in the U.S. (Ruscio et al., 2010), while Viana and Andrade (2012) observed the same pattern in Sao Paulo, Brazil (Viana and Andrade, 2012). The odds for females of the two countries were, respectively, 2.1 and 1.3, when compared to males (Ruscio et al., 2010; Viana and Andrade, 2012). This finding may suggest the importance of specific biological processes, and the unique contribution of gender, underlying the pathophysiology of OCD (Williams and Koran, 1997; Labad et al., 2005; Pauls et al., 2014).

Contrary to our initial hypothesis, the age of onset of first OCD symptoms and age at onset of meeting full diagnostic criteria for OCD were similar in U.S. subjects and Brazilians. A previous literature review found an earlier age of OCD onset in Brazilians when compared to other countries (Fontenelle et al., 2004). However, as highlighted by the review's authors, different studies tended to use discrepant definitions of age at onset [i.e. age when the symptoms were first noticed (see do Rosario-Campos et al., 2001) versus age at which the subject met full OCD criteria, involving symptoms interference and functional impairment (see Fontenelle et al., 2003)]. One of the strengths of the current study was that we were able to use the same definitions in both samples and reliably compare not only age at onset of first symptoms but also age at onset of full-blown OCD. These comparisons in our study suggest that the onset of first OCD symptoms and onset of OCD as a disorder may be similar across different cultures. This finding might reinforce the importance of biological factors, as opposed to environmental and/ or cultural factors, in the development of OCD.

In terms of psychiatric comorbidity, there were some significant differences between the U.S. and Brazilian subjects. For instance, the U.S. sample reported greater lifetime rates of alcohol and substance use disorders compared to the Brazilian sample. Although this may be clinically meaningful, the rates of these problems in fact mirror the rates seen in the general populations of the two countries. For example, the rate of alcohol use disorder in the general population of the U.S. is $28.8 \%$ (weighted average of two large population-based studies - Hasin et al., 2007 (Hasin et al., 2007), Kessler et al., 2005 (Kessler et al., 2005)). In Brazil, the prevalence of alcohol use disorder is $13.1 \%$ (Viana and Andrade, 2012). Notably, lower prevalence of alcohol-use/substance-use disorders was also described among individuals with other mental illnesses (functional psychoses, gambling disorder) in Brazil, as compared to patients from developed countries (Menezes and Ratto, 2004; Medeiros et al., 2015a, 2015b). The comorbidity of OCD and alcohol use disorder may interfere with treatment adherence and response, worsening OCD prognosis. Mental health professionals, particularly in the U.S., have to pay special attention to co-occurring alcohol use disorder in patients with OCD. Although the prevalence of alcohol use disorder may be affected by several environmental variables (public policies, alcohol availability, price and taxation), indulgence level is a cultural factor that may help explain the difference in the rates of this disorder between countries. Indulgence is a core cultural dimension and is defined as the tendency to seek pleasure and gratification of natural impulses associated with joy and fun (Hofstede, 2017). Low indulgence scores tend to reflect more restrained cultures with stricter social norms. The search for pleasure/gratification in a culture may be associated with a greater tendency to impulsivity and to develop impulsive/addictive behaviors such as alcohol use disorder. Fig. 1 displays the correlation between indulgence levels and prevalence of alcohol use disorder in different populous countries. Additional studies are needed to better investigate the association between this cultural element and other impulsive/addictive disorders.

Consistent with our initial hypothesis, we found a higher prevalence of GAD in the Brazilian sample. Moreover, the Brazilian group had more elevated rates of PTSD. The differences in these two comorbid disorders do not reflect the available data of the general population in both countries. Actually, the lifetime prevalence of each of these two disorders appears to be higher in the U.S. than in Brazil. GAD rates for the U.S. and Brazil are $6.7 \%$ and 3.7\%, respectively, while PTSD prevalence rates are $6.8 \%$ and $3.2 \%$ (Kessler et al., 2005; Lin et al., 2013). We cannot ascertain if, or to what extent, a causal relationship exists between OCD and these comorbid disorders in either sample. It is possible that an association between OCD, GAD and PTSD in Brazilian samples may reflect a culturally- or an environmentally-determined propensity. For example, Brazilians may present a tendency towards developing conditions characterized by cognitions with violent, unfortunate or traumatic themes, such as certain OCD obsessions, GAD preoccupations, or PTSD flashbacks. Accordingly, a previous review found an overrepresentation of obsessions with aggressive themes in treatment-seeking Brazilian OCD samples (de Silva, 2006). Additionally, some studies suggested that it may be not easy to disentangle obsessions, preoccupations or memories of something terrible happening (Keane et al., 1997; Grant et al., 2008; Stein et al., 2010), and this may explain higher prevalence of GAD and PTSD in the Brazilian subjects with OCD. An additional factor that may explain the lower prevalence of GAD and PTSD in the U.S. sample is medication status. The U.S. group used significantly more SSRIs, a first line medication for both GAD and PTSD. Further research is needed to explore the relationship between OCD and co-occurring conditions from a cultural perspective, including the extent to which each disorder might contribute to the other disorder's development and maintenance.

Our research has some limitations. First, this study assessed people with OCD who were seeking treatment in tertiary services and therefore may not represent OCD in general population in both countries. Second, this is a cross-sectional study where some clinical variables were evaluated retrospectively, and the data collection may have some level of recall bias, which may have affected the accuracy of some information. Third, the sample is not fully representative of the countries since the Brazilian sample was recruited in only five states and the U.S. participants were collected in only two states. Finally, the two groups used different instruments to assess the content of OCD symptoms. The U.S. and Brazilian samples were evaluated with, respectively, the YBOCS checklist and the DY-BOCS. These two scales present some significant differences in the approach to OCD symptoms. There are discrepancies in the dimensions, number of symptoms and vocabulary used. As a result, this study was not able to compare the content of obsessions and compulsions in a reliable manner. Despite the limitations, we believe that the large sample size and the innovativeness of directly comparing OCD variables across two countries of different levels of socioeconomic development make this study relevant to both clinicians and researchers.

Cross-cultural research on OCD is crucial, and collaborations such as this analysis create opportunities for large cross-cultural studies. Crosscultural research examining intrinsic OCD psychopathological features, neuropsychological and neurobiological aspects (e.g. neuroimaging, genetics and biological markers) cognitive functioning, family functioning, family accommodation and other social aspects (e.g. religion social support, stigma) may be particularly important for future projects with OCD sufferers. Future research comparing the content of OCD symptoms and cultural differences (attitude to sex, acceptance of aggression, etc) might provide additional insights regarding the etiology of obsessions and compulsions in different countries.

This study found several similarities and some differences in the clinical presentation of OCD in adults from the U.S. and Brazil, two countries with different social and cultural backgrounds. Some clinical elements that were similar between the two samples were: a) a higher proportion of females, b) similar ages at onset of the first OCD symptom and full-blown OCD, and c) similar prevalence of OCD spectrum disorders and mood disorders. On the other hand, we found significant differences between the two groups in the prevalence of some cooccurring disorders, particularly addictions (alcohol and substance use disorders), GAD and PTSD. Cultural aspects may help to explain these differences. Our results may provide much needed insight regarding the role of cultural elements on OCD clinical presentation. 


\section{General Population}

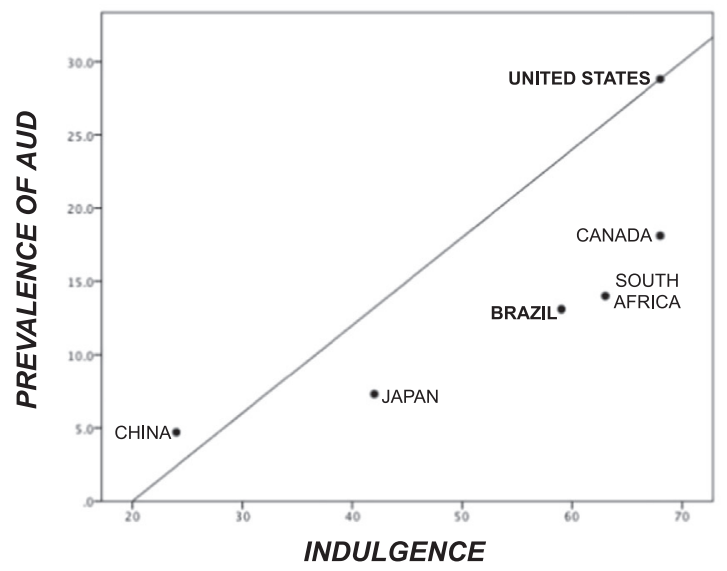

Pearson's Correlation Coefficient $=.823$

$$
p=.044
$$

\section{Treatment-Seeking $O C D^{b}$ Subjects}

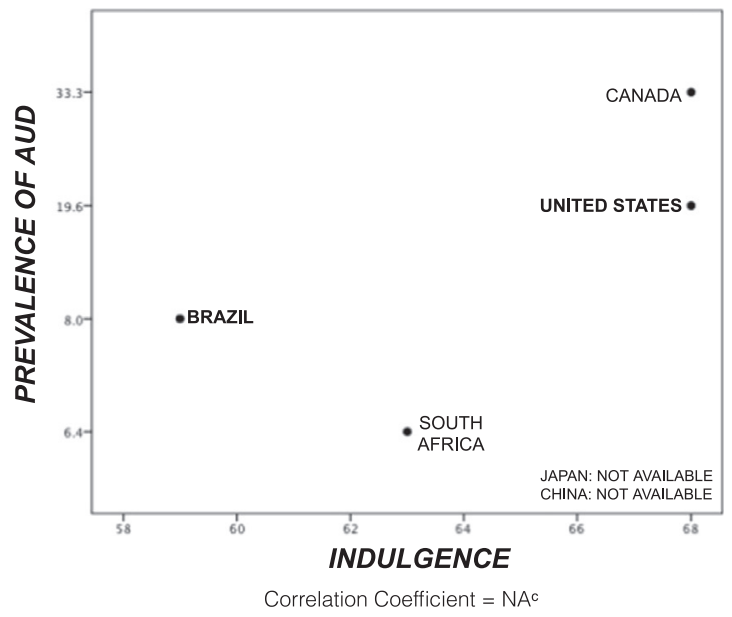

a) Indulgence = the tendency to seek pleasure and gratification of natural impulses associated with joy and fun (Hofstede, 2017).

b) OCD = obsessive compulsive disorder

c) It is not possible to calculate correlation coefficients for sample size $<5$ subjects.

Studies in the General Population= Brazil: Viana and Andrade, (2012); Canada: Pearson et al. (2013); China: Cheng et al. (2015); Japan: Ishikawa et al. (2016); South Africa: Herman et al., (2009); United States = weighted average of Kessler et al. (2005) and Hasin et al. (2007). Studies in Clinical Samples with OCD = Brazil (Current Study); Canada (Mayerovitch, 2003); South Africa: Locher et al. (2005); United States (Current Study).

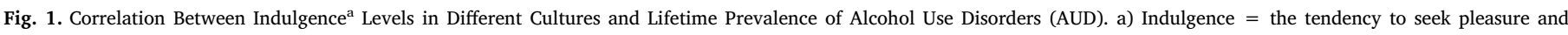

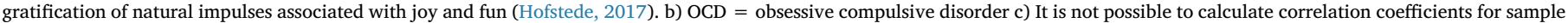

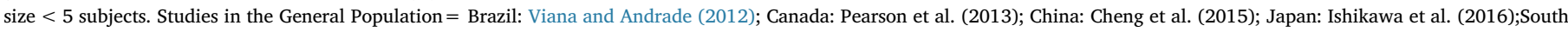

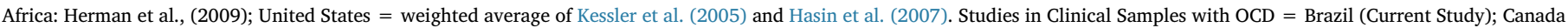
(Mayerovitch, 2003); South Africa: Locher et al. (2005); United States (Current Study).

\section{References}

Ackerman, D.L., Greenland, S., Bystritsky, A., Morgenstern, H., Katz, R.J., 1994. Predictors of treatment response in obsessive-compulsive disorder: multivariate analyses from a multicenter trial of clomipramine. J. Clin. Psychopharmacol. 14, 247-254.

Arrindell, W.A., Hatzichristou, C., Wensink, J., Rosenberg, E., van Twillert, B., Stedema, J., Meijer, D., 1997. Dimensions of national culture as predictors of cross-national differences in subjective well-being. Personal. Individ. Differ. 23 (1), 37-53.

Brakoulias, V., Starcevic, V., Belloch, A., Dell'Osso, L., Ferrão, Y.A., Fontenelle, L.F., Lochner, C., Marazziti, D., Martin, A., Matsunaga, H., Miguel, E.C., 2016. International prescribing practices in obsessive-compulsive disorder (OCD). Hum. Psychopharmacol.: Clin. Exp. 31 (4), 319-324.

Canino, G., Lewis-Fernandez, R., Bravo, M., 1997. Methodological challenges in crosscultural mental health research. Transcult. Psychiatry 34 (2), 163-184.

Cromer, K.R., Schmidt, N.B., Murphy, D.L., 2007. An investigation of traumatic life events and obsessive-compulsive disorder. Behav. Res. Ther. 45 (7), 1683-1691.

Field, A., 2005. Logistic regression. In: Discovering Statistics with SPSS, 2nd Ed. Sage, London. Ch. 6, 221-264.

First, M.B., Spitzer, R.L., Gibbon, M., Williams, J.B., 1997. User's Guide for the Structured Clinical Interview for DSM-IV Axis I Disorders SCID-I: Clinician Version. American Psychiatric Pub.

Fontenelle, L.F., Mendlowicz, M.V., Marques, C., Versiani, M., 2003. Early and late-onset obsessive compulsive disorder in adult patients: an exploratory clinical and therapeutic study. J. Psychiatr. Res. 37, 127-133.

Fontenelle, L.F., Mendlowicz, M.V., Marques, C., Versiani, M., 2004. Trans-cultural aspects of obsessive-compulsive disorder: a description of a Brazilian sample and a systematic review of international clinical studies. J. Psychiatr. Res. 38 (4), 403-411.

Fostick, L., Nacasch, N., Zohar, J., 2012. Acute obsessive compulsive disorder (OCD) in veterans with posttraumatic stress disorder (PTSD). World J. Biol. Psychiatry 13, 312.

Goodman, W.K., Price, L.H., Rasmussen, S.A., Mazure, C., Fleischmann, R.L., Hill, C.L., Heninger, G.R., Charney, D.S., 1989. The Yale-Brown obsessive compulsive scale: i. Development, use, and reliability. Arch. General. Psychiatry 46 (11), 1006-1011.

Grant, D.M., Beck, J.G., Marques, L., Palyo, S.A., Clapp, J.D., 2008. The structure of distress following trauma: posttraumatic stress disorder, major depressive disorder, and generalized anxiety disorder. J. Abnorm. Psychol. 117 (3), 662.

Grant, J.E., 2014. Obsessive-compulsive disorder. New Engl. J. Med. 371 (7), 646-653.

Hair Jr, J.F., Black, W.C., Babin, B.J., Anderson, R.E., Tatham, R.L., 2006. Multiple discriminant analysis and logistic regression. In: Multivariate Data Analysis, 6th ed. Prentice Hall, NewJersey, NY. Ch. 5, 221-302.

Hasin, D.S., Stinson, F.S., Ogburn, E., Grant, B.F., 2007. Prevalence, correlates, disability, and comorbidity of DSM-IV alcohol abuse and dependence in the United States: results from the national epidemiologic survey on alcohol and related conditions. Arch. General. Psychiatry 64 (7), 830-842.
Hofstede, G., 1991. Cultures and Organizations. Intercultural Cooperation and its Importance For Survival. Software of the Mind. Mc Iraw-Hill, London.

Hofstede, G., 2017. Cultural Dimensions. Available at 〈https://geert-hofstede.com/ culturaldimensions.html $>$ (accessed February 2017).

Horwath, E., Weissman, M.M., 2000. The epidemiology and cross-national presentation of obsessive compulsive disorder. Psychiatr. Clin. North Am. 23 (3), 493-507.

Ibáñez, A., Blanco, C., Donahue, E., Lesieur, H.R., Pérez de Castro, I., Fernández-Piqueras, J., Sáiz, Ruiz, J., 2001. Psychiatric comorbidity in pathological gamblers seeking treatment. Am. J. Psychiatry 158 (10), 1733-1735.

Keane, T.M., Taylor, K.L., Penk, W.E., 1997. Differentiating post-traumatic stress disorder (PTSD) from major depression (MDD) and generalized anxiety disorder (GAD). J. Anxiety Disord. 11 (3), 317-328.

Kessler, R.C., Berglund, P., Demler, O., Jin, R., Merikangas, K.R., Walters, E.E., 2005. Lifetime prevalence and age-of-onset distributions of DSM-IV disorders in the national comorbidity survey replication. Arch. General. Psychiatry 62 (6), 593-602.

Koran, L.M., 2000. Quality of life in obsessive-compulsive disorder. Psychiatr. Clin. North Am. 23 (3), 509-517.

Labad, J., Menchon, J.M., Alonso, P., Segalas, C., Jimenez, S., Vallejo, J., 2005. Female reproductive cycle and obsessive-compulsive disorder. J. Clin. Psychiatry 66 (4), 428-435 (quiz 546).

Lensi, P., Cassano, G.B., Correddu, G., Ravagli, S., Kunovac, J.L., Akiskal, H.S., 1996. Obsessive compulsive disorder. Familial-developmental history, symptomatology, comorbidity and course with special reference to gender-related differences. Br. J. Psychiatry 169, 101-107.

Lin, M., Lucas Jr, H.C., Shmueli, G., 2013. Research commentary-too big to fail: large samples and the p-value problem. Inf. Syst. Res. 24 (4), 906-917.

Lochner, C., Seedat, S., Du Toit, P.L., Nel, D.G., Niehaus, D.J., Sandler, R., Stein, D.J., 2005. Obsessive-compulsive disorder and trichotillomania: a phenomenological comparison. BMC Psychiatry 5 (1), 2.

Maj, M., 2005. Psychiatric research in low-and middle-income countries: the need for concrete action. Acta Psychiatr. Scand. 111 (5), 329-330.

Mancebo, M.C., Eisen, J.L., Pinto, A., Greenberg, B.D., Dyck, I.R., Rasmussen, S.A., 2006. The Brown longitudinal obsessive compulsive Study: treatments received and patient impressions of improvement [CME]. J. Clin. Psychiatry 67 (11), 1713 (20).

Marks, I.M., 1987. Fears, Phobias, and Rituals: Panic, Anxiety, and their Disorders. Oxford University Press on Demand.

Medeiros, G.C., Leppink, E.W., Yaemi, A., Mariani, M., Tavares, H., Grant, J.E., 2015a. Electronic gaming machines and gambling disorder: a cross-cultural comparison between treatment seeking subjects from Brazil and the United States. Psychiatry Res. 230 (2), 430-435.

Medeiros, G.C., Leppink, E., Redden, S., Mariani, M., Yaemi, A., Tavares, H., Grant, J.E., 2015b. The importance of cross-cultural research in addictions. Aust. N.Z. J. Psychiatry.

Menezes, P.R., Ratto, L.R., 2004. Prevalence of substance misuse among individuals with severe mental illness in São Paulo. Soc. Psychiatry Psychiatr. Epidemiol. 39 (3), 2127. 
Miguel, E.C., do Rosário-Campos, M.C., Prado, H.S., do Valle, R., Rauch, S.L., Coffey, B.J., Baer, L., Savage, C.R., O’Sullivan, R.L., Jenike, M.A., Leckman, J.F., 2000. Sensory phenomena in patients with obsessive-compulsive disorder and/or Gilles De La Tourette syndrome. J. Clin. Psychiatry 61 (2), 150-156.

Miguel, E.C., Ferrão, Y.A., Rosário, M.C., Mathis, M.A., Torres, A.R., Fontenelle, L.F., Hounie, A.G., Shavitt, R.G., Cordioli, A.V., Gonzalez, C.H., Petribú, K., 2008. The Brazilian research consortium on obsessive-compulsive spectrum disorders: recruitment, assessment instruments, methods for the development of multicenter collaborative studies and preliminary results. Rev. Bras. de Psiquiatr. 30 (3), 185-196.

Millet, B., Kochman, F., Gallarda, T., Krebs, M.O., Demonfaucon, F., Barrot, I., Bourdel, M.C., Olie, J.P., Loo, H., Hantouche, E.G., 2004. Phenomenological and comorbid features associated in obsessive-compulsive disorder: influence of age of onset. J. Affect. Disord. 79 (1), 241-246.

Murray, J., de Castro Cerqueira, D.R., Kahn, T., 2013. Crime and violence in Brazil: systematic review of time trends, prevalence rates and risk factors. Aggress. Violent Behav. 18 (5), 471-483.

Nedeljkovic, M., Moulding, R., Foroughi, E., Kyrios, M., Doron, G., 2012. Cultural issues in understanding and treating obsessive compulsive and spectrum disorders. Oxford Handbook ofObsessive Compulsive and Spectrum Disorders. Jan 1, 1-66.

Patel, V., Kim, Y.R., 2007. Contribution of low-and middle-income countries to research published in leading general psychiatry journals, 2002-2004. Br. J. Psychiatry 190 (1), 77-78.

Pauls, D.L., Abramovitch, A., Rauch, S.L., Geller, D.A., 2014. Obsessive-compulsive disorder: an integrative genetic and neurobiological perspective. Nat. Rev. Neurosci. 15 (6), 410-424.

Pinto, A., Mancebo, M.C., Eisen, J.L., Pagano, M.E., Rasmussen, S.A., 2006. The Brown Longitudinal Obsessive Compulsive Study: clinical features and symptoms of the sample at intake. J. Clin. Psychiatry 67 (5), 703.

Pourhoseingholi, M.A., Baghestani, A.R., Vahedi, M., 2012. How to control confounding effects by statistical analysis. Gastroenterology and Hepatology from bed to bench. 5(2), 79.

Ramos-Cerqueira, A.T., Torres, A.R., Torresan, R.C., Negreiros, A.P., Vitorino, C.N., 2008. Emotional burden in caregivers of patients with obsessive-compulsive disorder. Depress. Anxiety 25 (12), 1020-1027.

do Rosario-Campos, M.C., Leckman, J.F., Mercadante, M.T., Shavitt, R.G., Prado, H.D., Sada, P., Zamignani, D., Miguel, E.C., 2001. Adults with early-onset obsessivecompulsive disorder. Am. J. Psychiatry 158 (11), 1899-1903.
Rosario-Campos, M.C., Miguel, E.C., Quatrano, S., Chacon, P., Ferrao, Y., Findley, D., Katsovich, L., Scahill, L., King, R.A., Woody, S.R., Tolin, D., 2006. The dimensional Yale-Brown obsessive-compulsive scale (DY-BOCS): an instrument for assessing obsessive-compulsive symptom dimensions. Mol. Psychiatry 11 (5), 495-504.

Ruscio, A.M., Stein, D.J., Chiu, W.T., Kessler, R.C., 2010. The epidemiology of obsessivecompulsive disorder in the national comorbidity survey replication. Mol. Psychiatry 15 (1) (53 63).

Saxena, S., Paraje, G., Sharan, P., Karam, G., Sadana, R., 2006. The 10/90 divide in mental health research: trends over a 10-year period. Br. J. Psychiatry 188 (1), 81-82.

de Silva, P., 2006. Culture and obsessive-compulsive disorder. Psychiatry 5 (11), 402-404.

Stein, D.J., Fineberg, N.A., Bienvenu, O.J., Denys, D., Lochner, C., Nestadt, G., Leckman, J.F., Rauch, S.L., Phillips, K.A., 2010. Should OCD be classified as an anxiety disorder in DSM-V? Depress. Anxiety 27 (6), 495-506.

United Nations, 2013. World Population Prospects, the 2012 Revision. United Nations Department of Economic and Social Affairs, Population Division, Population Estimates and Projections Section, Jun.

Viana, M.C., Andrade, L.H., 2012. Lifetime Prevalence, age and gender distribution and age-of-onset of psychiatric disorders in the São Paulo metropolitan area, Brazil: results from the São Paulo megacity mental health survey. Rev. Bras. de Psiquiatr. 34 (3), 249-260.

Wilens, T.E., Biederman, J., Brown, S., Tanguay, S., Monuteaux, M.C., Blake, C., Spencer, T.J., 2002. Psychiatric comorbidity and functioning in clinically referred preschool children and school-age youths with ADHD. J. Am. Acad. Child Adolesc. Psychiatry 41 (3), 262-268.

Williams, K.E., Koran, L.M., 1997. Obsessive-compulsive disorder in pregnancy, the puerperium, and the premenstruum. J. Clin. Psychiatry 58 (7), 330-334 (quiz 335336).

Yorulmaz, O., Işık, B., 2011. Cultural context, obsessive-compulsive disorder symptoms, and cognitions: a preliminary study of three Turkish samples living in different countries. Int. J. Psychol. 46 (2), 136-143.

Yorulmaz, O., Gençöz, T., Woody, S., 2009. OCD cognitions and symptoms in different religious contexts. J. Anxiety Disord. 23 (3), 401-406.

Yorulmaz, O., Gençöz, T., Woody, S., 2010. Vulnerability factors in OCD symptoms: crosscultural comparisons between Turkish and Canadian samples. Clin. Psychol. Psychother. 17 (2), 110-121. 